\title{
Psychosocial problems and well being in institutionalized and non institutionalized children
}

\author{
G. Padmaja*, B. Sushma*, Swati Agarwal** \\ * Assistant Professor, Centre for Health Psychology, University of Hyderabad, Hyderabad, Telangana, India \\ ** Doctoral Scholar, Centre for Health Psychology, University of Hyderabad, Hyderabad, Telangana, India
}

\begin{abstract}
:
Background: Most of the research conclusively states that institutionalization of children has an adverse impact on their development, growth, and health. Institutionalized care becomes the only option to some children owing to several conditions like poverty, helplessness and others. Under such circumstances it is believed that institutional care is beneficial to them and a better option than home based care. The present study was intended to determine the role of type of care and gender on psychosocial problems and well being in children.

Method: A 2 X 2 factorial design with type of care and gender as the two factors was employed. 40 children under institutional care and 76 children living with their parents were assessed using the Strengths and Difficulties Questionnaire and the Adolescent Well Being Scale.

Results: Type of care has an impact on almost all the dimensions measured, with institutionalized children showing more internalizing problems, externalizing problems and poor well being.

Conclusions: Institutional care has an adverse impact on children leading to poor health outcomes. Care providers in the institutions have to adopt strengths and resilience based approach which focuses on protective factors and encourages the development of skills and traits that help in coping with difficulties. This would work towards improving the health of the institutionalized children.
\end{abstract}

Key Words: internalizing problems, externalizing problems, well being, children, type of care

\section{Introduction}

Institutional care has been defined by Browne (2009) as "a group living arrangement for more than ten children, without parents or surrogate parents, in which care is provided by a much smaller number of paid adult carers". In such a type of alternative care the guardianship of the children resides with the institution and there are individuals hired to act as caretakers of the children residing in the institution. Further the regimental system of institutional care is highlighted by Browne (2009) in his statement that "residential care implies an organised, routine and impersonal structure to the living arrangements for children (eg, all children sleep, eat and toilet at the same time) and a professional relationship, rather than parental relationship, between the adults and children". According to him a child can be considered to be under institutional care or is said to be institutionalized if he has been under institutional care for more than three months.

Institutional care is considered as an appropriate measure for providing care to orphan and destitute children in India. Numerous NGOs across the country provide institutional care to those children whose family is either unable to provide them with adequate care due to poverty, illness, etc or there are no immediate family members to take care of them as they are orphans. But most often there are children who are semi orphans, that is, either one of their parent has passed away and only one is alive. This makes it difficult to provide sufficient care to the child and hence the parents place the children under institutional care. There are a large number of children who are under institutional care in India. Though there are no official estimates of this number, Aangan India, an NGO, in its annual report of 2009-2010 puts the number at 4.5 million (2010).

The prevalence and levels of health problems among children under institutional care has been researched by many and they have found that these children do display poorer health when compared to others living with their families and within the wider community setup. Such children show poor adjustment levels (Hunshal and Gaonkar 2008), high emotional problems, difficulty in social interactions and many other indicators of maladjustment and poor well being.

Children in institutional care were found to have greater emotional problems (Ford et al. 2007; Erol, et al. 2010). They tend to be emotionally withdrawn (Zeanah, et al. 2005) and experience emotional loneliness (Han and Choi 2006; Ptacek et al. 2011).

Institutionalized children experience multiple emotional problems and have inadequate resources to deal with them effectively, quite often resulting in childhood psychopathology. Depression is one of the 
disorders seen among children under institutional care. Studies comparing the institutionalized and non institutionalized children found differences in the level of depression with institutionalized children displaying higher levels (Dell'aglio and Hutz 2004; Wathier and Dell'aglio 2007). They are also known to have more social problems than other children according to Palacios et al. (2013) who compared 40 internationally adopted, 50 institutionalized children and 58 community based children.

On the other hand different results were seen in a study consisting of 1357 institution-living and 1480 community-living children across five developing countries including India. In this study Whetten et al (2009) found that children in institutions had fewer emotional difficulties as they could focus on their needs rather than their families'. Children from poor communities where their caregivers may not be able to provide them with appropriate care may be better off when in institutional care in some scenarios as these children would often have to forego their emotional needs for their families'.

Poor health in adolescence may be an early indicator of the future health problems. The type of care in institutions may be detrimental to the development of the child. Care provided to children, influences their growth and development. Research studies on institutionalization of children show that there is a substantial effect of institutional care on the health of institutionalized children (Vorria, et al. 2003; Shechory and Sommerfeld 2007; Nowacki and Schoelmerich 2010). But despite this the number of children in institutional care in India is increasing. There appear to be only few research studies about children in India who are vulnerable and at risk. This study was carried out to determine the role of institutionalization on psychosocial problems viz internalizing and externalizing problems as well as on well being in children in an Indian city. The objectives of the study were to determine the role of type of care and gender on internalizing and externalizing problems and well being in children.

\section{Method}

Design - A 2X2 factorial between-participants design with two Independent variables was used. Variables were type of care- institutional care and home based care, and gender - boys and girls.

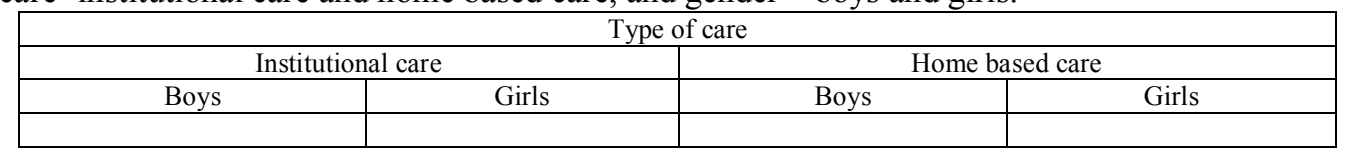

Participants- a sample of 40 institutionalized adolescents - including 22 boys and 18 girls and 76 home based children including 37 boys and 39 girls were part of this study. They were all in the age group of 12- 15 years. The study was carried out in the twin cities of Hyderabad and Secunderabad, India

Instruments - Strengths And Difficulties Questionnaire (SDQ) (Goodman, 1997), an extensively used behavioural screening questionnaire, is meant for children who are in the age range of 11 to 16 years. This brief self report questionnaire has 25 items. It measures five dimensions of behaviour that includes emotional symptoms ( 5 items), conduct problems ( 5 items), hyperactivity/inattention ( 5 items), peer relationship problems ( 5 items) and prosocial behaviour (5 items). Excluding the prosocial behaviour dimension, this gives a strength score, the score of the other dimensions when added together give a score called difficulties score. An alternate division of the SDQ gives 'internalizing problems' (emotional and peer symptoms, 10 items), 'externalizing problems' (conduct and hyperactivity symptoms, 10 items) and the prosocial scale (5 items). Each item has three responses and the scoring and interpretation of the SDQ is as per the manual.

Adolescent Well Being Scale (Birleson, 1980) is an 18 item tool for children between the ages of 11 to 16 years. This scale aims to know about different aspects of an adolescent's life and their feelings about them. Each item has three responses and the adolescent has to indicate the extent to which the statement applies to him/her that is never, sometimes or most of the time. The manual is the basis for scoring and interpretation of the Adolescent Well Being Scale. A score of 13 or more is stated to be indicative of probable depressive disorder with increasing score suggesting higher levels of depression. On the other hand a low score is indicative of good well being

Procedure - An NGO that provides institutional care to children for the past 25 years was approached for this study. After the permission of the institution head was obtained, the study was carried out with those children who were in the required age group and gave their assent to participate in the study. The inclusion criteria for participation for institutionalized children was that the children had to be under institutional care for at least a year and that they were in the age range of 12 to 15 years. Children from juvenile homes, short stay homes and boarding schools were excluded.

For the community based sample, that is children who were living with their parents, local government run schools were approached and their permission sought and informed consent taken. Again the children in the age range of 12- 15 years who were willing to participate were included in the study and their assent was obtained. Children from the schools belonged to lower socio economic status, a similar financial background as that of the institutionalized children. 
Statistical analysis - Two way ANOVA was used to study the main effect of type of care on internalizing problems, externalizing problems and well being. Main effect of gender on the internalizing problems, externalizing problems and well being was assessed as well. The interaction effect of type of care and gender on internalizing problems, externalizing problems and well being was also determined.

Results - The summary of the two way ANOVA results are presented in table 1. On analyzing the emotional problems, it was seen that type of care had a main effect as the $\mathrm{F}$ ratio $(1,112)=16.618, \mathrm{p}<0.001$. Children who were under institutional care reported a higher level of emotional problems than those children who were under home based care. Gender also showed a significant main effect with an $\mathrm{F}$ ratio $(1,112)=6.035, \mathrm{p}<0.05$, indicating girls to have reported having more emotional problems in comparison to boys. The $\mathrm{F}$ ratio $(1,112)$ for the interaction effect was $1.635, \mathrm{p}>0.05$ indicating no interaction of gender and type of care on emotional problems.

Table 1. Summary table of $2 \mathrm{X} 2$ ANOVA results

\begin{tabular}{|c|c|c|c|c|c|c|c|}
\hline & & Type of care & & & Gender & & $\begin{array}{l}\text { Interaction } \\
\text { Type of care } \\
\text { X Gender }\end{array}$ \\
\hline & $\begin{array}{l}\text { Institutional } \\
\text { care (40)Mean } \\
\text { (SD) }\end{array}$ & $\begin{array}{c}\text { Parental care/ } \\
\text { home based } \\
\text { care (76) } \\
\text { Mean (SD) }\end{array}$ & F ratio & $\begin{array}{c}\text { Male (59) } \\
\text { Mean (SD) }\end{array}$ & $\begin{array}{c}\text { Female (57) } \\
\text { Mean (SD) }\end{array}$ & F ratio & F ratio \\
\hline Emotional Problems & $4.88(2.09)$ & $3.49(1.73)$ & $16.618 * * *$ & $3.64(1.89)$ & $4.30(2.01)$ & $6.035^{*}$ & 1.635 \\
\hline Peer Problems & $3.20(1.65)$ & $3.13(1.46)$ & .066 & $3.19(1.57)$ & $3.12(1.49)$ & .002 & .581 \\
\hline $\begin{array}{l}\text { Internalizing } \\
\text { Problems }\end{array}$ & $8.08(2.90)$ & $6.62(2.41)$ & $9.358 * *$ & $6.83(2.79)$ & $7.42(2.52)$ & 3.151 & 1.873 \\
\hline $\begin{array}{l}\text { Hyperactivity } \\
\text { Problems }\end{array}$ & $3.75(1.69)$ & $2.79(1.94)$ & $6.774 * *$ & $3.03(2.04)$ & $3.21(1.76)$ & .015 & 2.747 \\
\hline Conduct Problems & $4.03(1.83)$ & $3.01(1.57)$ & $13.530 * * *$ & $3.27(1.72)$ & $3.46(1.74)$ & $5.142 *$ & $21.475 * * *$ \\
\hline $\begin{array}{l}\text { Externalizing } \\
\text { Problems }\end{array}$ & $7.78(2.54)$ & $5.80(2.56)$ & $17.02 * * *$ & $6.31(2.81)$ & $6.67(2.61)$ & 2.139 & 2.562 \\
\hline Depression & $13.80(4.41)$ & $10.55(3.43)$ & $19.245^{* * *}$ & $11.59(4.14)$ & $11.75(4.06)$ & .358 & .182 \\
\hline Well Being ${ }^{\#}$ & $13.80(4.41)$ & $10.55(3.43)$ & $19.245^{* * *}$ & $11.59(4.14)$ & $11.75(4.06)$ & .358 & .182 \\
\hline
\end{tabular}

Note. $* \mathrm{p} \leq 0.05, * * \mathrm{p} \leq 0.01, * * * \mathrm{p} \leq 0.001$

${ }^{\#}$ Low scores on well being scale are indicative of good well being and high score suggests poor well being.

The main effect of type of care yielded an $\mathrm{F}$ ratio $(1,112)=.066, \mathrm{p}>0.05$ indicating no significant effect of type of care on peer problems. Gender also showed no significant main effect on peer problems as the $\mathrm{F}$ ratio $(1,112)=.002, \mathrm{p}>0.05$. The interaction effect of type of care and gender yielded an $\mathrm{F}$ ratio $(1,112)=$ $.581, \mathrm{p}>0.05$ indicating no interaction effect of gender and type of care on hyperactivity among children.

The children under institutional care reported higher level of internalizing problems than children under home based care as indicated by the main effect of type of care as it yielded an $\mathrm{F}$ ratio $(1,112)=9.358, \mathrm{p}<0.01$. There was no main effect of gender on internalizing problems as the $F$ ratio $(1,112)=3.151, p>0.05$. This indicates no significant differences among boys and girls in the level of internalizing problems. The interaction effect of gender and type of care was also not significant as the F ratio $(1,112)$ was $1.873, p>0.05$.

There was a main effect of type of care on the level of hyperactivity among the children as it yielded an $\mathrm{F}$ ratio $(1,112)=6.774, \mathrm{p}<0.05$. Hyperactivity level was higher among children under institutional care compared to those children who were based at home. Gender effect was not significant as it yielded an F ratio $(1,112)=.015, \mathrm{p}>0.05$ indicating almost equal level of hyperactivity among boys and girls. The interaction effect of gender and type of care was also not significant as the $F$ ratio $(1,112)=2.747, p>0.05$.

The conduct problems was higher for children under institutional care than for children living with their parents as indicated by the main effect of type of care which showed that $F$ ratio $(1,112)=13.530, p$ $<0.001$. The main effect of gender showed that $\mathrm{F}$ ratio $(1,112)=5.142, \mathrm{p}<0.05$, indicating that girls had higher conduct problems in comparison to boys. Further the interaction effect of type of care and gender was also significant with an $\mathrm{F}$ ratio $(1,112)=21.475, \mathrm{p}<0.001$. This indicates that gender effects were different depending upon the type of care. Girls who were under institutional care had significantly higher level of conduct problems than boys under institutional care, where as among children living with their parents, boys had a higher level of conduct problems.

Main effect of type of care on externalizing problems was significant as $\mathrm{F}$ ratio $(1,112)=17.02$, $\mathrm{p}<0.001$ indicating that children under institutional care had higher level of externalizing problems than children under home based care. Gender did not show a significant main effect as $F$ ratio $(1,112)=2.139, p>0.05$. There was no significant interaction effect of type of care and gender as the $F$ ratio $(1,112)=2.562, p>0.05$.

The children under institutional care had higher level of depression than those children who were under home based care as indicated by the main effect of type of care which yielded an F ratio $(1,112)=19.245$, $\mathrm{p}<0.001$. There was no main effect of gender as $\mathrm{F}$ ratio $(1,112)=.358, \mathrm{p}>0.05$ indicating no differences in boys 
and girls in their level of depression. Further the interaction effect of type of care and gender also showed $\mathrm{F}$ ratio $(1,112)=.182, p>0.05$ indicating no significant interaction effect in the level of depression. The mean score of the institutionalized children on the scale was above 13 indicating high depression and poor well being.

\section{Discussion}

Emotional problems are higher in the institutionalized children as found by other studies. A risk factor for high emotional problems in these children is lack of emotional control or self regulation (Aguilar-Vafaie et al. 2011). Further it was found from a qualitative study which interviewed 44 youth aging out of the institutions, who reported to being resistant to seeking emotional support (Samuels and Pryce 2008).

Studies have found that institutionalized children had high social problems. But in the present study there was no difference in the level of peer problems. The present sample of institutionalized children attended a neighbourhood government school. Each child had other children from the institution in his class and hence was not the lone institutionalized child. Further as the classmates were also from the same neighbourhood and the institution did allow the children to visit their friends in the neighbourhood, it could be the reason for improved peer relations among them.

One of the effects of institutional living on children appears to be hyperactivity which is supported by studies which have found that there is high prevalence of it among institutionalized children (Egelund and Lausten 2009). The present study has also got similar results. Even after being removed from institutional care the after effects of it remain with many post institutionalized children continuing to show hyperactivity (Wiik et al. 2011). Conduct problems are also highly prevalent among institutionalized children. The prevalence of conduct problems is generally higher among boys as compared to girls (Ford et al. 2007; Egelund and Lausten 2009). But in the present study though this was consistent with parental care children, the institutionalized children showed contradictory results. This could be due to poor self regulation, form of emotional outbursts and poor attachment with caregivers among the girls.

Internalizing and externalizing problems were both found in high levels among institutionalized children in line with existing research. Aguilar-Vafaie et al. (2011) in their study on orphan adolescent boys $(n=71)$ and girls $(n=69)$ looked at the various factors that put the children at risk for developing internalizing and externalizing problems. The risk factors for internalizing problems included neighbourhood poverty and peers who show deviant behaviour and for externalizing problems it was gender. Besides risk factors, the protective factors that resulted in better outcomes for children include perceived feelings of intimacy and connectedness and positive attitudes towards school in female adolescents.

One important factor that can be noted from the above results is that social connections play a crucial role in developing or reducing psychological problems. Social support and positive social interactions with others decrease the vulnerability of children to negative outcomes. So enhancing the quality of relationships and promoting stable, secure attachment with peers and caregivers can bring about positive outcomes among these children.

The results of the present study showing high depression and low well being in institutionalized children are concurrent with contemporary research. Dell'aglio and Hutz (2004) compared 105 institutionalized children with 110 children who lived with their families on depression and found differences between the groups with females living in institutions to have significantly higher scores. This was corroborated by Wathier and Dell'aglio (2007) in their study on 257 Brazilian children, 130 of whom lived in institutions. Well being of children under institutional care continues to be poor. According to them even if the institution is able to arrest the increase in psychopathology, it does not guarantee well being and good quality of life.

Though there is an adverse impact of institutional care on children it is the only major alternative care option in India with an increasing propensity of parents placing their children under this type of care. The major reasons for institutionalization of children are poverty, semi-orphans or parents' or child's health problems. There is a need to explore other care options for children whose parents are unable to provide adequate parental care but may be able to do so with some support from the community or govt.

Increasing number of organizations are cropping up that provide institutional care for children. They need to realize that providing the basic amenities is no longer enough in ensuring that the life of the child is good. There needs to be a paradigm shift in the focus of institutional care emphasizing upon promotion of well being and improvement of quality of life. A more positive psychological perspective has to be undertaken to ensure that the child is happy, content and optimistic about his future. Children under institutional care have to be encouraged to have aspirations and goals for themselves which could set the basis of change for their next generation.

\section{Conclusion}

Firstly, it is evident from the study that home based care is better than institutional care, but institutionalization sometimes remains the only option available to families in dire straits owing to various 
factors. There is a need to explore other care options for children whose parents are unable to provide adequate parental care but may be able to do so with some support from the community or government provided support services. The increasing number of children being placed under institutional care can be reduced by ensuring adequate help and support to families at the right time and place.

At the same time institutional care is the only alternative in some scenarios and thus it needs a major overhaul in its functioning and services. An assessment of children's counseling needs and an examination of the corresponding services provided by the institution have to be undertaken. There needs to be a paradigm shift in the focus of institutional care in not just providing basic amenities to children but also promotion of well being and improvement of quality of life of institutionalized children. A more positive psychological perspective has to be undertaken to ensure that the child is happy, content and optimistic about his future.

A strengths and resilience based approach, which focuses on promotion of protective factors and encourages the development of skills and traits that help in coping with difficulties, is needed to further improve the standard of care in the institutions. Tailor made interventions satisfying the unmet psycho-social needs and enhancing the strengths, while helping the children gain control over the identified weaknesses, need to be developed. Resilience based interventions that help move the child away from the cycles of risk and vulnerability and push them towards a path of growth, aspirations and well being may be greatly helpful. Thus, psycho-social interventions, particular resilience based, appear to be highly essential.

\section{Acknowledgement}

No external funding was received for this study. The authors have declared that they have no competing or potential conflicts of interest. The authors would like to thank the participating schools and institutions for granting permission to carry out the study in their organizations and for their support and cooperation.

\section{Conflict of interest}

The authors declare that they have no conflict of interest.

\section{References}

[1]. Aangan Trust (2010). Annual Report March 2009- March 2010, Aangan India, Mumbai Retrieved on December 15, 2012 from http://aanganindia.org/pdf/Annual\%20Report-2009-2010.pdf

[2]. Aguilar-Vafaie, M. E., Roshani, M., Hassanabadi, H., Masoudian, Z. \& Afruz, G. A. (2011). Risk and protective factors for residential foster care adolescents. Children and Youth Services Review, 33(1), 1-15. doi:10.1016/j.childyouth.2010.08.005

[3]. Birleson, P. (1981). The validity of Depressive Disorder in Childhood and the Development of a Self-Rating Scale; a Research Report. Journal of Child Psychology and Psychiatry. 22: 73-88. doi: 10.1111/j.1469-7610.1981.tb00533.x

[4]. Browne, K. (2009). The risk of harm to young children in institutional care. London, Save the Children UK. Retrieved on December 15, 2012 from http://www.crin.org/docs/The_Risk_of_Harm.pdf

[5]. Dell'Aglio, D. D., \& Hutz, C. S. (2004). Depression and school achievement of institutionalized children and adolescents. Psicologia: Reflexão e Crítica, 17(3), 351-357.

[6]. Egelund, T. \& Lausten, M. (2009). Prevalence of mental health problems among children placed in out-of-home care in Denmark. Child \& Family Social Work Special Issue: High Risk Youth: Evidence on Characteristics, Needs and Promising Interventions, 14 (2), 156-165. doi:10.1111/j.1365-2206.2009.00620.x

[7]. Erol, N., Simsek, Z., \& Münir, K. (2010). Mental health of adolescents reared in institutional care in Turkey: challenges and hope in the twenty-first century. European Child and Adolescent Psychiatry, 19(2), 113-124. doi: 10.1007/s00787-009-0047-2

[8]. Ford, T., Vostanis, P., Meltzer, H. \& Goodman, R. (2007). Psychiatric disorder among British children looked after by local authorities: comparison with children living in private household. The British Journal of Psychiatry, 190, 319-325. doi:10.1192/bjp.bp.106.025023

[9]. Goodman, R. (1997). The Strengths and Difficulties Questionnaire: A Research Note. Journal of Child Psychology and Psychiatry, $38,581-586$

[10]. Han, E. \& Choi, N. (2006). Korean institutionalized adolescents' attributions of success and failure in interpersonal relations and perceived loneliness. Children and Youth Services Review, 28 (5), 535-547. doi:10.1016/j.childyouth.2005.06.002

[11]. Hunshal, S. C., \& Gaonkar, V. (2008). A study on adjustment of institutionalized children. Karnataka Journal of Agricultural Sciences, 21(4), 548-552

[12]. Nowacki, K. \& Schoelmerich, A. (2010). Growing up in foster families or institutions: Attachment representation and psychological adjustment of young adults. Attachment and Human Development, 12 (6), 551-566. doi: 10.1080/14616734.2010.504547

[13]. Palacios, J., Moreno, C. \& Roman, M. (2013). Social competence in internationally adopted and institutionalized children. Early Childhood Research Quarterly, 28, 357-365

[14]. Ptacek, R., Kuzelova, H., \& Celedova, L. (2011). Social and Emotional Loneliness in Children in Foster and Institutional Care. European Psychiatry, 26 (1), 338 Abstracts of the 19th European Congress of Psychiatry. doi:10.1016/S0924-9338(11)72047-8

[15]. Samuels, G. M. \& Pryce, J. M. (2008). "What doesn't kill you makes you stronger": Survivalist self-reliance as resilience and risk among young adults aging out of foster care. Children and Youth Services Review, 30 (10), 1198-1210. doi:10.1016/j.childyouth.2008.03.005

[16]. Vorria, P., Papaligoura, Z., Dunn, J., van IJzendoorn, M. H., Steele, H., Kontopoulou, A., \& Sarafidou, Y. (2003). Early experiences and attachment relationships of Greek infants raised in residential group care. The Journal of Child Psychology and Psychiatry, 44(8), 1208-20.

[17]. Wathier, J. L., \& Dell'Aglio, D. D. (2007). Depressive symptoms and stressful events in children and adolescents in the institutionalized context. Revista de Psiquiatria do Rio Grande do Sul, 29(3). Retrieved from http://dx.doi.org/10.1590/S010181082007000300010 
[18]. Whetten, K., Ostermann, J., Whetten, R. A., Pence, B. W., O’Donnell, K., Messer. L. N., Thielman, N. M., \& The Positive Outcomes for Orphans (POFO) Research Team. (2009). A Comparison of the Wellbeing of Orphans and Abandoned Children Ages 6-12 in Institutional and Community-Based Care Settings in 5 Less Wealthy Nations. PLoS ONE, 4(12), e8169. doi:10.1371/journal.pone.0008169

[19]. Wiik, K. L., Loman, M. M., Van Ryzin, M. J., Armstrong, J. M., Essex, M. J., Pollak, S. D. \& Gunnar, M. R. (2011). Behavioral and emotional symptoms of post-institutionalized children in middle childhood. Journal of Child Psychology and Psychiatry, 52 (1), 56-63. doi:10.1111/j.1469-7610.2010.02294.x

[20]. Zeanah, C. H., Smyke, A. T., Koga, S. F., Carlson, E. \& The Bucharest Early Intervention Project Core Group. (2005). Attachment in Institutionalized and Community Children in Romania. Child Development, 76(5), 1015-1028. doi:10.1111/j.14678624.2005 .00894 